\title{
ENTREVISTA CON ADRIANA PAGANO
}

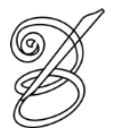 \\ Gleiton MALTA* \\ Universidad de Brasília, Brasil
}

ntes de todo agradecerte la disponibilidad (te voy a tutear, ya que me siento muy a
gusto contigo y no me arriesgo a utilizar el voseo). El curso de traducción español de
la Universidad de Brasilia cumple en 201910 años. Para celebrarlo, una de las actividades es esta, es decir, la publicación de un número especial en la Belas Infiéis sobre la traducción español-portugués. De esa manera, es una alegría y un honor para nosotros que formes parte de esta celebración, una vez que creo que hay mucha gente que no sabe que eres argentina. Pues, te doy la bienvenida para esta pequeña entrevista.

Gleiton Malta (GM): ¿Cuál es el rol del idioma en el proceso traductor? ¿El par lingüístico influye en las estrategias y/o en el desempeño del traductor?

Adriana Pagano** (AP): Si hablamos de la enseñanza de la traducción, pensamos en el proceso traductor dentro de un modelo de cómo se desarrolla la competencia traductora. El modelo que adoptamos en nuestro Laboratorio Experimental de Traducción, en la UFMG, es el modelo del grupo PACTE de Barcelona. En este modelo, los conocimientos del idioma integran la llamada subcompetencia bilingüe, la cual es fundamental para que se pueda desarrollar la competencia traductora. Pero hay otras subcompetencias, relacionadas al conocimiento de dominio, conocimientos sobre la tarea de traducir y otros, que también son importantes. Uno podría decir que la subcompetencia bilingüe, o sea los conocimientos de los idiomas con los cuales trabajamos, es la base, el punto de partida. Pero vale recordar que el conocimiento bilingüe no es suficiente para ser traductor. Como lo advierte la investigadora Amparo Hurtado: "Todo traductor es bilingüe, pero no todo bilingüe es traductor".

Ojo que la subcompetencia bilingüe es, en el caso del traductor, un conocimiento distinto del que se observa en el hablante de un idioma o un aprendiz de un idioma. Se trata de un conocimiento de aspectos comparados de los idiomas, como si fuera una gramática comparada en un nivel de granularidad muy fino, muy sensible. 
Sobre el español (que yo lo llamo "castellano") y el portugués, el modelo de PACTE se aplica a cualquier par lingüístico. No hay pares de idiomas que sean más o menos fáciles y no es correcto afirmar, como se lo hace habitualmente, que traducir del castellano al portugués, o viceversa, sea más fácil que en otros pares. El nivel de complejidad de la traducción está mucho más relacionado a aspectos culturales que al parentesco lingüístico.

GM: La difusión del conocimiento académico, incluso el volcado para la Traductología, se da básicamente de forma monolingüe, es decir, en inglés ¿Qué lugar ocupan la lengua portuguesa y la lengua española con respecto a la difusión del conocimiento académico/científico?

AP: De hecho, hay que reconocer que la mayor parte de la bibliografía circula en lengua inglesa, pero hoy ya tenemos bibliografía en castellano y portugués, sobretodo libros introductorios, libros didácticos y también artículos en periódicos internacionales. Por otra parte, hay que ver al inglés como lengua franca; así se justifica su uso en el diálogo internacional, por ejemplo, entre investigadores en Latinoamérica e investigadores asiáticos o de otros continentes que no hablen los llamados idiomas europeos.

GM: ¿Dedicas tiempo y espacio en sus proyectos de investigación para la lengua castellana y para la lengua portuguesa? ¿Por qué?

AP: Sí, a pesar de haber trabajado mucho con la lengua inglesa, también realicé trabajos comparando el portugués y el castellano, así como en mis clases de traducción siempre llevo ejemplos de estos dos idiomas e intento mostrarles a los alumnos la importancia de investigar la especificidad de las lenguas y no menospreciarlas, porque se cree (erróneamente) que son semejantes. Muchos alumnos piensan que el castellano y el portugués son lenguas muy parecidas y no aprecian su valor o la riqueza de significados que podemos construir en cada una de ellas.

A mí me gusta analizar y comparar el castellano y el portugués para explorar la capacidad de significar de cada idioma, como diría el lingüista Michael Halliday. Por ejemplo, la diferencia entre "darse cuenta" en castellano y " dar-se conta" (contrastado con "perceber") en portugués. O el uso diario en castellano de "acercar" y "acercarse" y los significados que estos verbos construyen. Además, uno puede comparar los distintos usos en sus contextos y pensar la traducción en un ambiente más amplio, como diría, el lingüista Christian Matthiessen en su magnífico texto "Theenvironments of translation". Fíjate que cuando uno recibe una boleta digital de gas o luz en Argentina, nos llega con un mensaje: "Adriana, te acercamos tu 
factura"; acá en Minas Gerais, una boleta de agua por correo electrónico nos llega con el mensaje: "chegou sua conta por e-mail". No hace falta traducir "te acercamos" por una expresión análoga en el nivel gramatical, porque en el nivel del contexto de situación, la traducción es otra, basada mucho más en la boleta que nos llega en Minas Gerais. ¿Me explico?

GM: Últimamente estás desarrollando proyectos de investigación relacionados a esfuerzo/carga cognitiva. El más reciente es el "Cognitive load and potential cost of ELF in academic contexts”. ¿Podrías hablarnos algo sobre el proyecto? ¿Qué rol cumplen el portugués y el castellano en él?

AP: Este proyecto que estamos desarrollando ahora es un proyecto experimental y, como dijiste, analiza la carga cognitiva durante el proceso traductor. Es un proyecto con la Universidad de Ciencias Aplicadas de Zúrich. Queremos comparar el esfuerzo cognitivo de los participantes durante la redacción de un resumen académico en su lengua materna (L1), la redacción de un resumen en inglés, pensado como lengua franca(ELF), y la post-edición de la traducción automática de la L1 al inglés. En la universidad de Zúrich, el experimento se está haciendo con estudiantes cuya primera lengua es el alemán y tienen que publicar sus artículos en lengua inglesa, y acá, en nuestra universidad, con estudiantes brasileños e hispanohablantes que también tienen que publicar en inglés. El alemán, el portugués y el castellano son lenguas reconocidas internacionalmente, pero aun así no tienen el estatus del inglés en el espacio académico. Por eso se necesita investigar las dificultades y la presión que sienten los alumnos para escribir en una lengua que no es su L1.

GM: Otro proyecto que desarrollas en el LETRA es el que trata de las Ontologías. ¿Qué resultados tienen, aunque preliminares, respecto al impacto del sistema lingüístico en los procesos de producción multilingüe? ¿Hay algún resultado relacionado al par español<>portugués?

AP: Una ontología es una forma de organizar significados, generalmente dentro de un dominio. Una ontología digital es un archivo que nos permite registrar esa organización de significados y compartirla con otros archivos en una red de relaciones. En nuestro Laboratorio, trabajamos con ontologías para organizar las funciones gramaticales y semánticas con las cuales se crean los significados en una lengua. No estamos pensando en terminologías o diccionarios convencionales.

Es como si fuera un diccionario semántico de significados en potencial. Nosotros utilizamos una ontología de base sistémico-funcional, conocida como GUM (Generalized 
Upper Model). Por ejemplo, para expresar el dolor físico en portugués o inglés o castellano, hay recursos gramaticales prototípicos, que "generan" (este término viene de la ciencia de la computación) cláusulas comparables, como "estou com dor de cabeça", "I have a headache" y "me duele la cabeza". Esos recursos gramaticales están registrados y organizados en nuestra ontología. No hay registro de palabras, sino de funciones semánticas y gramaticales, que son las que van a generar cláusulas como las de nuestro ejemplo.

GM: Eres una de las defensoras de la interface Estudios de Traducción y Lingüística sistémicofuncional. ¿Por qué has elegido esa teoría lingüística para fundamentar (¿poner de relieve?) posibles diferencias y semejanzas entre sistemas lingüísticos en ambientes relacionados a la traducción?

AP: La teoría sistémico-funcional es una teoría multilingüe por excelencia; tiene una base semántica sólida, intrínsecamente conectada a la gramática. Esa base semántica nos permite comparar lenguas y explicar qué recursos de la gramática se usan para generar un significado análogo en dos lenguas, cuál sería la manera más habitual de expresar, como en nuestro ejemplo

172 anterior,un dolor físico en una lengua. Esa comparación es muy útil para decidir cuál es la forma más adecuada de traducir un significado a otra lengua o cómo enseñar diferencias entre los idiomas. También es útil para el análisis textual o del discurso.

GM: La lengua portuguesa no está, todavía, totalmente descripta. ¿Qué impacto eso tiene para los estudios que usan la LSF como teoría lingüística como soporte para el análisis intertextual en contextos de traducción?

AP: Como Michael Halliday siempre decía, para traducir, primero hay que comparar los idiomas, y para comparar los idiomas, hay que describir su gramática, su léxico y sus mecanismos de funcionamiento con la granularidad más fina posible; cuanto más específica es una descripción, tanto más nos permite situarla en relación con otra lengua y tomar decisiones sobre cuál es la traducción más adecuada. El día que tengamos una descripción amplia del portugués, en un nivel de granularidad fino, vamos a avanzar mucho más en la enseñanza de la traducción y en aplicaciones automáticas de asistencia a la traducción.

GM: Cierta vez he oído de un colega que la traducción e incluso la interpretación del español hacia el portugués era desnecesaria. ¿Qué opinión tienes acerca de la afirmación? 
AP: No me sorprende ese comentario. Es más, recientemente, un ambientalista que conocí en un taller sobre terminología en el área ambiental dijo algo parecido, pero sobre el inglés: "¿para qué traducirla a otros idiomas si toda la terminología sobre medioambiente está en inglés?"

Como diría Michael Halliday, la lengua construye nuestra realidad, nuestro pensamiento, nuestro mundo. La terminología en el área ambiental es crucial para el futuro de la humanidad. ¿Cómo nos podemos poner de acuerdo, si no intentamos entender lo que significa en cada cultura "naturaleza", "vida silvestre", "conservación", etc.? En ese taller sobre terminología en el área ambiental, había participantes de Latinoamérica, Europa, China, Corea, Japón y a cada palabra, cada término que discutíamos, nos dábamos cuenta de que a veces creemos que hablamos de un mismo concepto y utilizamos la misma palabra en inglés, pero en el fondo cada cultura construye un significado distinto. Puede parecer una paradoja, pero no lo es. El inglés es necesario para que podamos comunicarnos, para que nosotros hablemos con un chino, un coreano, un japonés; sin embargo, cada uno tiene que volver a su lengua, revisar los significados y después negociarlos de nuevo en, y con, el inglés.

GM: ¿Podrías dejar un mensaje a los estudiantes de traducción español<>portugués y futuros investigadores sobre nuestro quehacer, el de traductor y/o el de investigador?

AP: Soy una eterna optimista y no le tengo miedo a las máquinas. La tecnología nos abre puertas inimaginables, fantásticas para el estudio de la lengua y la traducción. Pero hay que hacerlo con método, con sistematización. Menos intuición y más investigación.

Para la investigación, el ejercicio y la enseñanza de la traducción, aconsejo no tenerle miedo a la tecnología y no quedarse en los comentarios superficiales sobre las lenguas. "Think grammatically", nos dejó en su legado Halliday; "grammatically" en el sentido hallidayano, o sea, investigando el uso de la lengua con una base teórica sólida y explícita, desconfiando de las explicaciones casuísticas.

Sobre la relevancia de las Humanidades, la lengua, no me canso de decir que el siglo veintiuno es el siglo de las humanidades. Puede que sea de las "humanidades digitales", pero humanidades al fin. Nunca fue tan urgente y necesario el estudio de la lengua para entender los fenómenos sociales. Como nos dijo Halliday, en la gramática de la lengua hay "una teoría de la experiencia humana".

¡Mucha suerte y gracias totales! 


\footnotetext{
* Gleiton MALTA - Doutor em Estudos Linguísticos (2015) pela Universidade Federal de Minas Gerais. Mestre em Linguística Aplicada (2009) pela Universidade de Brasília e especialista em Gestão Escolar (2009) pela Universidade de Brasília e em Metodologia do Ensino da Língua Espanhola (2006) pelo Centro Universitário Internacional (UNINTER). Graduado em Letras - Espanhol (2001) pela Universidade de Brasília. Professor adjunto no bacharelado em Letras/Tradução - Espanhol e no Programa de Pós-Graduação em Estudos da Tradução da Universidade de Brasília. Brasília, Distrito Federal, Brasil.

Currículo acadêmico: http://lattes.cnpq.br/0525598075310277

ORCID: https://orcid.org/0000-0003-0359-4046

E-mail: gleitonmalta@gmail.com

** Adriana Silvina PAGANO - Doutora em Estudos Literários (1996) pela Universidade Federal de Minas Gerais. Mestre em Inglês: Estudos Linguísticos e Literários (1991) pela Universidade Federal de Santa Catarina. Bacharel em Tradução (1987) pela Universidad Nacional de La Plata, Argentina. Licenciada em Letras Inglês (1987) pela mesma instituição. Realizou pesquisas de pós-doutorado na Universität des Saarlandes (2010), Alemanha, e na University of Massachusetts Amherst (2000), EUA. É professor titular na Universidade Federal de Minas Gerais. Bolsista de produtividade em pesquisa do CNPq - nível 1D. Belo Horizonte, Minas Gerais, Brasil.

Currículo acadêmico: http://lattes.cnpq.br/9048531014341931

ORCID: https://orcid.org/0000-0002-3150-3503

E-mail: apagano@ufmg.br
} 